\title{
A Model for the Development of the Key Competence of Specialists of a Network Self-learning University
}

\author{
Belova Elena ${ }^{1}$, Volegzhanina Irina ${ }^{2}$, Tayurskiy Anatoly ${ }^{1}$
}

\author{
${ }^{1}$ Siberian Federal University, Krasnoyarsk, Russia \\ ${ }^{2}$ Siberian Transport University, Novosibirsk, Russia \\ *Email: erarcher@mail.ru
}

\begin{abstract}
Modern challenges and increasing requirements for the effectiveness of higher education organisations actualise the search for new solutions. The authors see such a solution in developing the key competence of specialists of the innovative network self-learning university. The research aims at theoretical substantiation and development of a predictive model for developing the key competence of specialists of a network self-learning university. A new approach is proposed to improve the effectiveness and competitiveness of the university through the continuous development of the key competence of its specialists on a motivational and value basis in the process of creating a network self-learning university. As the key competence of university specialists, we consider their key managerial competence, which depends on the solution of complex professional tasks and the successful management of their professional activities. The methodological basis was competence-based and axiological approaches. Based on the results of the analysis of scientific literature, the results of the experiment, the professional tasks of three groups of specialists of the network self-learning university were determined, and the key universal professional tasks for them were identified. As a modelling result, the structure of the key managerial competence of specialists of a network self-learning university and a model for developing this competence has been developed. The essence of the concepts of "network self-learning university", "key managerial competence of university specialists" is revealed; the structure of key managerial competence of specialists is substantiated, and the predictive model of continuous development of this competence is characterised, which reflects this development process in the conditions of the motivational and value basis of ongoing formal, informal and informational professional education.
\end{abstract}

Keywords: Key managerial competence of specialists, Network self-learning university, Professional effectiveness, Continuing education, Self-education.

\section{INTRODUCTION}

The increasing requirements for the activities of all higher education organisations and industry universities in particular, which actively develop online education, innovative activities $[1 ; 2]$ in the context of Industry 4.0, particularly actualise the problem of finding new solutions that improve the performance of industry organisations of higher education following the principles of lifelong education [3; 4]. Universities that train personnel for various production fields (for example, railway transport) strive to improve the performance indicators of their activities by turning to innovative concepts and technologies [5]. The authors of the study propose a new solution to the problem of improving the performance of such universities, which is quite universal. The main idea is to establish a modern university as a network self-learning university based on the continuous development of the key competence of its specialists and the creation of other conditions that ensure this formation. Among these conditions, considered earlier, we distinguish: "network professionaldeveloping educational space" [6]; motivational-value attitude of specialists to the management of their professional activities; exchange of knowledge, experience and mutual learning; inclusion of specialists 
in problem-solving activities in the process of work and training under additional professional education programs; association of partners in a triple network (internal, modular-concentric and dynamic); network and team interactions of subjects of the triple network; motivation of specialists and the system of continuing professional education [7], which includes group implicit knowledge, values, traditions, styles of interactions as part of the motivational and value a corporate culture of the university.

We understand a network self-learning university as a university with a triple network structure, whose specialists "constantly develop readiness to improve the effectiveness of their professional activities in the process of continuing education, self-study and professional self-educational activities" [7, p. 124].

The importance of creating a network self-learning university (SLU) actualises the study of the characteristics of the key competence of specialists and the justification of the model of its continuous development. Within the framework of this study, the SLU specialists include employees of the faculty, administrative and managerial, and educational and auxiliary personnel of the university.

In the context of the digital transformation of higher education and increasing requirements for the effectiveness of universities, there is a constant complication of the tasks facing all university specialists, whose professionalism is subject to new requirements. Currently, SLU employees can't be successful teachers or specialists of a narrowly subject orientation without developing self-management skills and managing their professional activities. The purpose of the study is the theoretical substantiation and development of a predictive model for developing the key competence of SLU specialists.

\section{REVIEW OF SCIENTIFIC LITERATURE ON THE PROBLEM}

Competence as a scientific category in the international discourse on education [8] and the competence-based approach to vocational education studied by many scientists, including Adolf V.A., Derkach A.A., Raven J., Tatur Yu.G., Khutorskoy A.V., Khutmacher V. et al. A.V. Khutorskoy understands competence as an integrated personality quality that combines personal qualities, ways of activity and valuesemantic attitude [9]. V.A. Adolf considers the professional competence of a teacher as the ability to independently apply professional knowledge, skills, and skills in the conditions of professional activity and its digital transformation [10].

Scientists study the stages of formation of a key competence management system [11]; develop a model of key competencies for any organisation [12]; identify cooperation and teamwork as key competencies of specialists in the context of Industry 4.0 [13]. Consideration of adult continuing education in the context of lifelong learning, which directs specialists and teaching staff to develop self-management skills for the development of organisational culture [14], the development of competencies allows people to act confidently in professionally difficult situations for the purpose of sustainable self-development and growth of the organisation [15]. The problems of creating a selflearning organisation in which a favourable climate is formed for the organisation of independent training of employees [16], which will ensure the implementation of the five disciplines introduced by P. Senge [17], are investigated.

However, the understanding of the key managerial competence of SLU specialists as an organisation of a new formation has not been formed, which may be explained by the complexity of managing specialists in their professional activities in pristine conditions. This makes it necessary to develop and substantiate the structure of the key managerial competence of SLU specialists and the model of its development.

\section{METHODOLOGY (MATERIALS AND METHODS)}

The competence approach made it possible to identify the key managerial competence that ensures the solution of universal professional tasks and the improvement of the effectiveness of specialists, to consider the components of this key managerial competence. The axiological approach contributed to the study of the motivational and value basis for developing the key competence of university specialists, ensuring the successful solution of urgent professional tasks and improving the effectiveness of professional activity through the involvement of specialists in continuous training, self-education and mutual learning.

Based on the scientific literature analysis results and the results of empirical studies conducted earlier [7], the professional tasks of the educational and auxiliary, administrative and managerial personnel, the teaching staff of the SLU were identified, and the key universal professional tasks for them were identified, which made it possible to substantiate the essence of the key managerial competence universal for these specialists. As a modelling result, the structure of the key managerial competence of SLU specialists and a model of its continuous development has been developed.

\section{RESEARCH RESULTS, DISCUSSION}

Each employee solves professional tasks and emerging problems in his professional and selfeducational activities to fulfil his official duties. Thus for professionals holding positions of administrative staff, it 
becomes an essential task of improving the efficiency and competitiveness of the University; fundraising and marketing; creating a system of continuous education and self-education specialists and conditions for their professional self-educational activity (P-SA); the involvement of new actors in the triple network SLU and the development of productive networking; application of the skills system-creative thinking in solving various production situations, that can successfully adapt to the new environment of digital transformation, etc. The tasks facing teaching and support staff in SLU, allocated: career guidance and recruitment of students to implement in University programs; the timely and proper execution of documentation; the performance indicators of their professional activities; exchange of experience, training, self-learning and peer teaching to adapt in a changing environment; effective networking with students, employers, colleagues and other stakeholders triple net SLU; inclusion in strategic planning, project activities, etc.; scientific and pedagogical staff of SLU solve a variety of professional tasks: development and implementation of educational programs in accordance with the requirements of the new Federal educational standards and professional standards, including using digital technologies; implementation of scientific research activities; publication of scientific works; identify and meet the educational needs of students; continuing education and self-education, exchange of knowledge and experience in the process of network communications etc.

At the same time, through the analysis and generalisation of the above and other professional tasks of SLU specialists, we identify tasks that are crucial, universal for all three groups of specialists: managing their professional activities and responsibility for improving its effectiveness; timely identification and accurate formulation of problems and tasks of managing their professional activities, P-SA and their timely effective resolution; managing their interaction with colleagues, subjects of the triple network and students; training, self-learning and mutual learning in the process of network communications; development of systemcreative thinking in the process of solving various problems in professional activities, allowing to adapt to new conditions; inclusion in strategic planning and forecasting; development of regulations for the main types of activities, etc. The listed professional tasks of SLU specialists characterise to a greater extent their managerial activities rather than narrowly professional activities in the performance of official duties. In the context of the formation of the SLU, it is vital to have key managerial competence not only for university managers but also for each specialist from the position of managing his professional activities.

Thus, as a result of an interdisciplinary analysis of the concepts of key adult competencies and the tasks of specialists of administrative and managerial, teaching and support staff and scientific and pedagogical staff of the university, we single out the key managerial competence of SLU specialists as a key competence.

When considering the essence of the key managerial competence of a specialist (KMC) of the SLU, the previously formulated concepts of "managerial competence of heads of educational institutions in the field of culture" [18] and "key managerial competence of employees of a network self-learning organisation of additional professional education" are taken as a basis [7]. We consider the key managerial competence of SLU specialists in the context of acquiring skills for managing their professional activities and understand it as "a quality of personality manifested in a willingness to identify on time, holistically analyse, accurately formulate problems and tasks, find and implement the most appropriate and effective management solutions that enhance the effectiveness of their professional activities" [ibid., p. 135]. Based on the results of previous studies, it has been proved that the development of key managerial competence of specialists ensures their readiness for effective management of their professional activities [ibid.], which contributes to improving performance SLU as a whole.

When developing the structure of the key managerial competence of SLU specialists, we were guided by the solved professional tasks, the requirements of the professional standards of three groups of specialists, presenting it as a mega-competence, including "three groups of competencies: self-educational, professionalspecial and socio-personal" [7, p. 90]. Self-educational competencies of the SLU specialist contribute to the effective implementation of his self-education, selfdevelopment and professional self-educational activities. Professional and unique competencies provide solutions to actual practical professional problems based on problem-solving skills. The social and personal competencies of the SLU specialist ensure successful communication in the network, team interactions, emotional stability, health preservation and valuesemantic orientation of self-education and selfdevelopment. Based on the analysis, the authors concluded that there are motivational-value (meanings and values of specialists and SLU), cognitive-synergetic (knowledge gained in the process of learning, selfeducation, self-study), activity-problem-solving (activities to identify and resolve professional problems) and evaluative-reflexive (turning back, self-assessment, reflection) the KMC components of SLU specialists (Figure 1).

The development of the KMC of the SLU specialist is carried out through the improvement of the skills of problem-solving activities. In formal continuing education, group problem-solving research activities aimed at identifying and formulating professional problems in the process of individual and teamwork of 


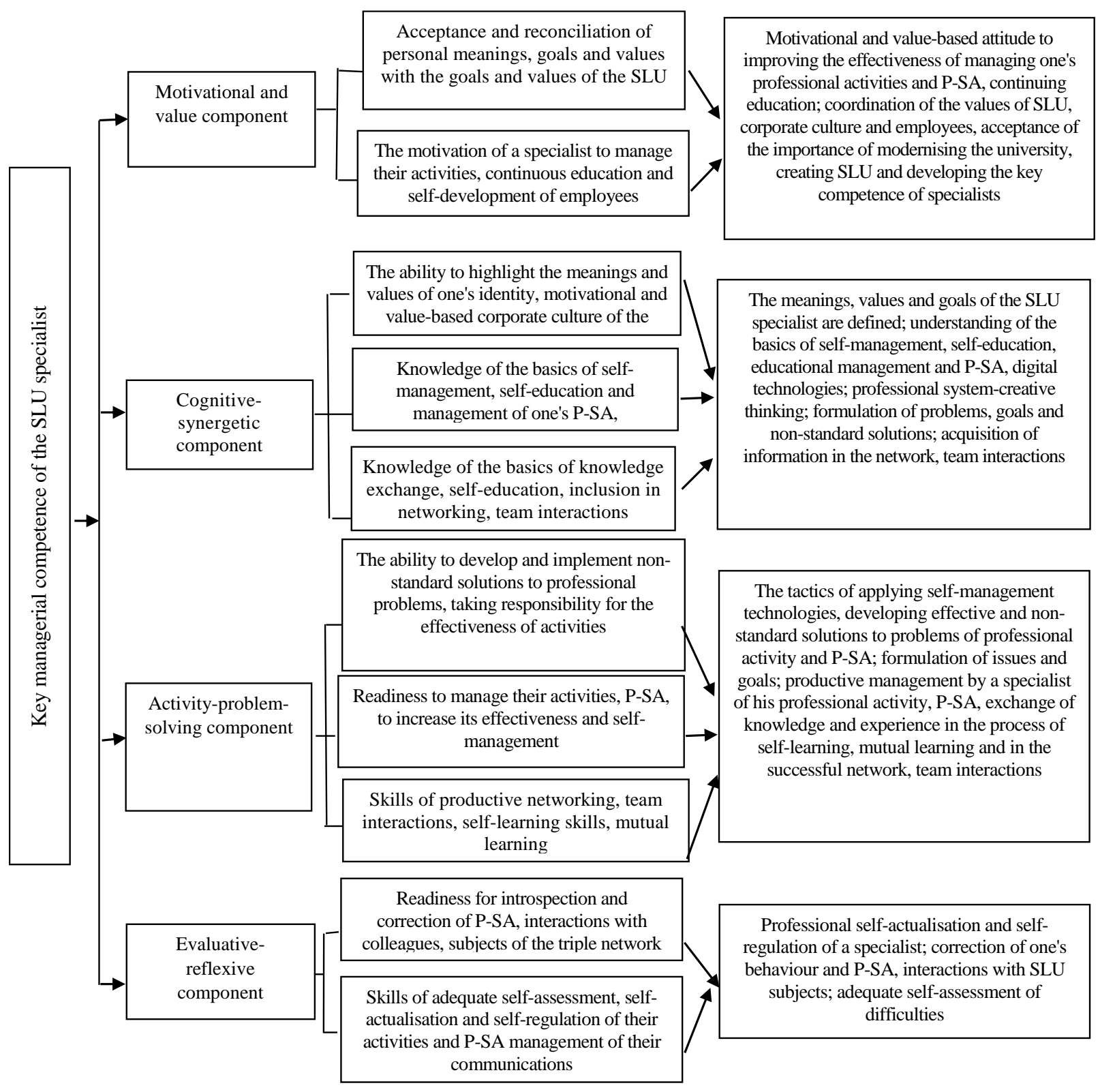

Figure 1 Components of the key management competence of the SLU specialist.

students are implemented in the classes of the advanced training program.

Based on the results of this activity, specialists develop projects for solving specific professional problems, which they can then implement in practice.

The actualisation of the development of the key competence of SLU specialists has determined the importance of developing a scheme of a predictive model for the development of key managerial competence (Figure 2). This model reflects the integrity of the educational process implemented based on competence-based and axiological methodological approaches. And also "the use of methods of individual and collective problem-solving mental activity, self-education, mutual learning" [7, p. 192].
This educational process includes the identification of professional deficits, the development of the content of elements of the system of continuing professional education (CPE) using digital technologies, including the content of professional development programs in the field of management and adaptation to constant changes; training of specialists in the program "Self-management and selfeducation of specialists of a network self-learning university", modelling of such problematic situations that actualise the educational needs of trained specialists; the use of active and interactive educational, distance and problem-solving technologies, consulting both in the process of training specialists and then in the process of their training, reflection after training, self-actualisation and correction of actions by a specialist, self-learning and 
Social order: modernisation of organisations of the higher education system through the creation of SLU and actualisation of the development of the key competence of its specialists

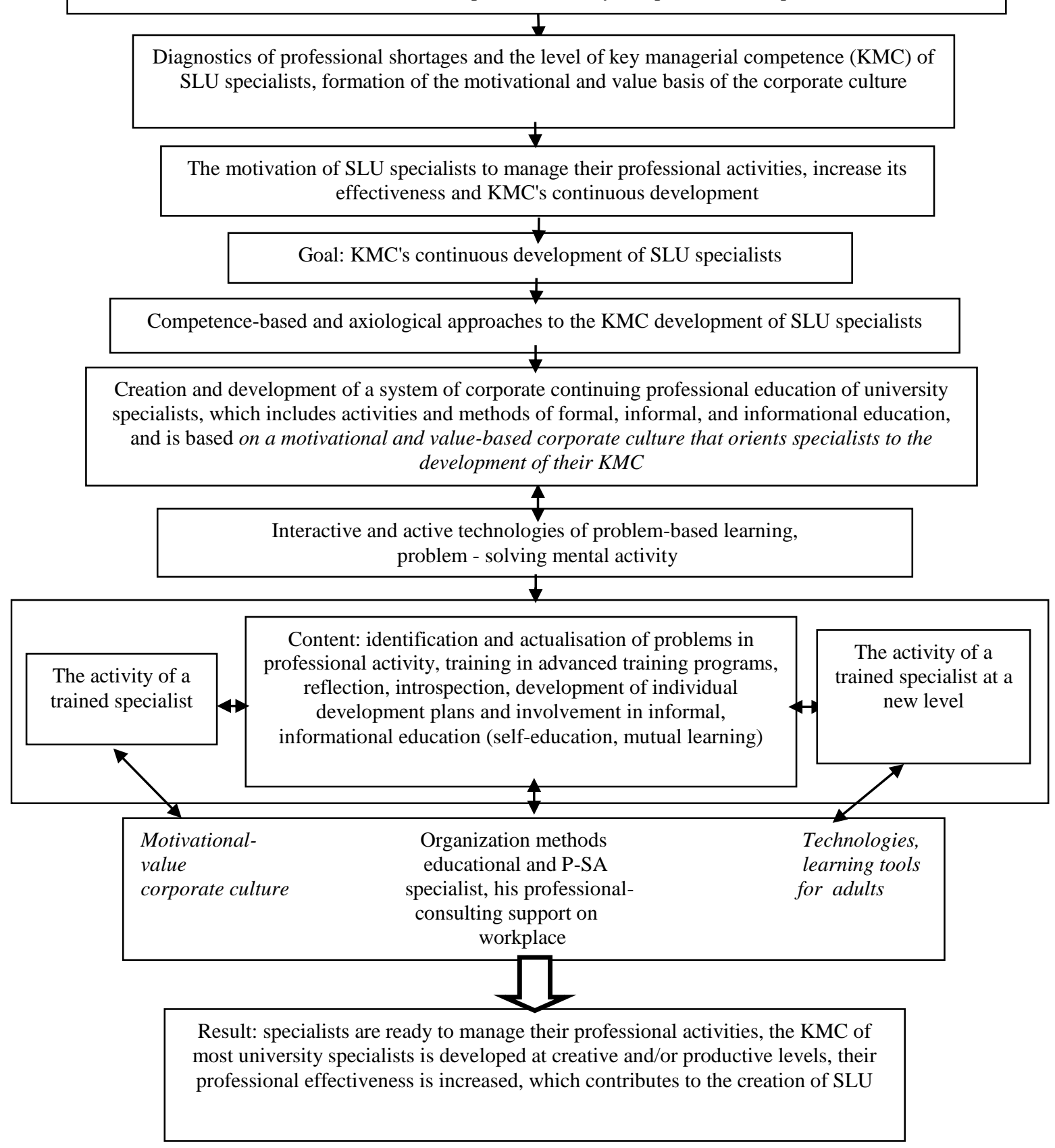

Figure 2 Model of development of key management competence of SLU specialists.

mutual learning in the process of network, team interactions and the process of work.

SLU specialists' key management competence (KMC) develops continuously and cyclically. It is vital for university leaders striving to create SLU to develop a motivational and value-based corporate culture that promotes reflection of specialists and self-actualisation of professional deficits, KMC's continuous development in the process of formal education and then in the process of informal, informal education.

For this, it is essential to create conditions for developing P-SA, an activity that relies on self-education, selfdevelopment, mutual learning in the work process and the use of self-management skills and problem-solving mental activity in solving professional tasks. In the study, four levels of KMC's development of SLU specialists were identified: maladaptive, adaptive, productive and creative. 
According to the results of early studies, it was revealed that "the development of key managerial competence in more than $55 \%$ of employees at the creative and/or productive levels" [7, p. 187] allows us to speak about the sufficiency of the development of this key competence and the creation of one of the conditions for the successful transformation of the university into SLU. The positive attitude of specialists to increase the level of this competence is facilitated by their motivation to manage their professional activities, which is facilitated by the motivation and value of a corporate culture of the university, self-actualisation of identified deficiencies and achieving significant results through inclusion in continuing education. At the same time, it is essential to ensure further continuous updating of the constant formal, non-formal and informal education system to meet the changing requirements and challenges of our time.

\section{CONCLUSION}

Thus, the conclusion is made about the presence of cognitive -synergetic, activity -problem-solving, motivational-value and evaluative-reflexive components of the key managerial competence of SLU specialists; this competence harmoniously integrates selfeducational, professional-special and socio-personal competencies, and the developed predictive model of its development reflects this development process in the conditions of the created system of continuous (formal, informal and informational) vocational education on a motivational-value basis from the formation of social order to the development of key managerial competence of specialists on a creative and/or productive levels.

\section{REFERENCES}

[1] M. Kebritchi, A. Lipschuetz, L. Santiague, Issues and challenges for teaching successful online courses in higher education: A literature review, Journal of Educational Technology Systems 1(46) (2017) 4-29.

[2] C.M. Toquero, Challenges and opportunities for higher education amid the COVID-19 pandemic: The Philippine context, Pedagogical Research, No. 5(4), 2020.

[3] S.M. Khalid et al., Exploring the effects of a modified higher education performance service quality model on organisational sustainability: the case of Malaysian polytechnics, Sustainability 13(14) (2021) 8105.

[4] J. Lu, C. Laux, J. Antony, Lean Six Sigma leadership in higher education institutions, International Journal of Productivity and Performance Management, 2017.

[5] V. Khabarov, I. Volegzhanina, Knowledge Management System of an Industry-Specific
Research and Education Complex (by an Example of Transport Personnel Training). IOP Conf. Ser.: Earth Environ. Sci., Vol. 403, XII International Scientific Conference on Agricultural Machinery Industry 10-13 September 2019, Don State Technical University, 2019. DOI: https://doi.org/10.1088/1755-1315/403/1/012197

[6] E.N. Belova, Networked professional-developing educational space [Setevoe professional'norazvivayushchee obrazovatel'noe prostranstvo], Open and distance education [tkrytoe i distancionnoe obrazovanie] 1(65) (2017) 5-11. DOI: https://doi.org/10.17223/16095944/65/1

[7] E.N. Belova, Formation and development of a network self-learning organisation [Stanovlenie i razvitie setevoj samoobuchayushchejsya organizacii], Siberian Federal University [Sibirskij federal'nyj universitet], 2020, 412 p. DOI: https://doi.org/10.12731/ER0489.19112021

[8] J. Glaesser, Competence in educational theory and practice: a critical discussion. Oxford Review of education 45(1) (2019) 70-85. DOI: https://doi.org/10.1080/03054985.2018.1493987

[9] A.V. Khutorskoy, Structure and content of the competence textbook [Struktura i soderzhanie kompetentnostnogo uchebnika], Higher Education Today [Vysshee obrazovanie segodnya] 1 (2020) 8 13.

DOI: https://doi.org/10.25586/RNU.HET.20.01.P.08

[10] V.A. Adolf, D.V. Grak, Transformation of professional competence of a teacher in the conditions of the digital overcoming of the pandemic [Transformaciya professional'noj kompetentnosti pedagoga $\mathrm{v}$ usloviyah cifrovogo preodoleniya pandemii], Siberian Pedagogical Journal [Sibirskij pedagogicheskij zhurnal] 6 (2020) 7-14. DOI: https://doi.org/10.15293/18134718.2006.01

[11] V.V. Yatsenko, I.O. Naidis, Competence management of the organisation. Maturity level of project activity [Upravlenie kompetenciyami organizacii. Uroven' zrelosti proektnoj deyatel'nosti], Competence [Kompetentnost'] 8 (2020) 38-45. DOI: https://doi.org/10.24411/1993$\underline{8780-2020-10805}$

[12] D. Blancero, J. Boroski \& L. Dyer, Key competencies for a transformed human resource organisation: Results of a field study, Human resource management 35(3) (1996) 383-403. DOI: https://doi.org/10.1002/(SICI)1099050X(199623)35:3\%3C383::AIDHRM6\%3E3.0.CO;2-T 
[13] J. Čermáková \& L. Rolínek, Determination of key competencies for Industry 4.0, In Scientific Conference INPROFORUM, 2020, pp. 119-125.

[14] O.P. Osipova, O.A. Shklyarova, Self-management resource in improving professional viability and development of the managerial culture of teaching staff [Resurs samomenedzhmenta $\mathrm{v}$ povyshenii professional'noj zhiznesposobnosti i razvitii upravlencheskoj kul'tury pedagogicheskih rabotnikov], Problems of modern education [Problemy sovremennogo obrazovaniya] 5 (2020) 202-213. DOI: https://doi.org/10.31862/2218$\underline{8711-2020-5-202-213}$

[15] M. Rieckmann, Learning to transform the world: Key competencies in Education for Sustainable Development. Issues and trends in education for sustainable development 39 (2019) 39-59.

[16] I. Hutasuhut, S.A.Z. Adruce, \& V. Jonathan, How a learning organisation cultivates self-directed learning, Journal of Workplace Learning, 2021.

[17] P.M. Senge, The fifth discipline, Measuring Business Excellence, 1997.

[18] E.N. Belova, Managerial competence of the head [Upravlencheskaya kompetentnost' rukovoditelya], Krasnoyarsk State Pedagogical University named after V.P. Astafiev [Krasnoyarskij gosudarstvennyj pedagogicheskij universitet im. V.P. Astaf'eva], 2013, 272 p. DOI: https://doi.org/10.12731/ER0488.16112021 